\title{
Apendicite aguda: epidemiologia, sintomas, exames complementares e riscos para complicações
}

\author{
Autores: Daniel Hazaki dos Santos, Juliana Mika Kato \\ Orientadores: Adilson Costa Rodrigues Junior, Edivaldo Massazo Utiyama
}

Introdução: A apendicite aguda (AA) é uma das indicações mais comuns de cirurgia de emergência, e, apesar de descrita há mais de um século, ainda apresenta diversos elementos epidemiológicos e etiológicos pouco compreendidos. Dados nacionais da doença são raros, e o papel diagnóstico de exames complementares ainda é controverso na literatura mundial. Tendo em vista tais desafios, buscamos contribuir para a melhor compreensão global da AA com dados brasileiros, visando também auxiliar no diagnóstico e tratamento rápidos da doença.

Objetivos: Caracterizar epidemiologia, história, sinais, exames laboratoriais e de imagem e desfechos de AA em uma população brasileira, e também seus respectivos papeis na discriminação de casos complicados de não-complicados da doença.

Metodologia: Avaliação retrospectiva dos registros médicos de 966 pacientes que tiveram AA confirmada por descrição cirúrgica e/ou exame anatomopatológico em um hospital terciário. Casos complicados foram dados como apêndice gangrenoso ou perfurado, em função do exame anatomopatológico. Os dados foram avaliados estatisticamente em busca de diferenças, tomando por base um nível de confiança de $95 \%$. Utilizamos o test t para as variáveis quantitativas contínuas e o teste de chi-quadrado para as categóricas.

Resultados: Os casos estudados foram mais incidentes em homens, na terceira década de vida, nos meses quentes do ano e em indivíduos brancos. Não houve diferença entre casos complicados e não-complicados em se tratando de sexo, idade, número de atendimentos médicos prévios, presença de febre ou seu nível, número de leucócitos, valor de PCR ou bilirrubinas totais. Houve diferença, contudo, na quantidade de dias de história no momento da procura pelo serviço e de dias de internação, maiores nos casos complicados. A característica álgica mais frequente foi dor em fossa ilíaca direita, seguida de dor difusa e, por último, migratória. Febre foi o dado clínico mais frequente depois da dor, seguido de náuseas/ vômitos e anorexia. Sintomas gastrointestinais e urinários foram raros. Exames de imagem foram solicitados em 2/3 dos pacientes com AA e em 3/4 das mulheres e dos idosos. Ultrassonografia foi o exame mais solicitado em crianças e mulheres, e tomografia computadorizada, em idosos.

Discussão e conclusão: Os achados corroboram os dados da literatura quanto à epidemiologia da doença, reforçando o efeito climático sobre a sua incidência. Houve discordância com outros estudos ao não haver diferença de casos complicados e não-complicados em função da idade e sexo, que talvez possa ser explicado por diferenças metodológicas. Nossos dados sugerem que a ocorrência de complicações seja mais devida à demora pela procura por atendimento do que pelo atraso diagnóstico hospitalar, bem como já foi demonstrado por outros autores. Embora alterados, os valores de leucócitos, proteína C-reativa e bilirrubinas totais não discriminam os casos complicados dos não-complicados, sugerindo sua utilidade apenas como instrumento auxiliar para o diagnóstico da AA. Exames de imagem foram solicitados, como tendência mundial, na maioria dos pacientes, em especial nas mulheres e idosos, grupos de maior dificuldade diagnóstica. 